\title{
Ranking and mapping the contributions by overseas Chinese strategy scholars: A systematic and relevant analysis
}

\author{
Weiwen $\mathrm{Li}^{1} \cdot$ Peter Ping $\mathrm{Li}^{2} \cdot$ Cheng $\mathrm{Shu}^{3}$. \\ Meihua Zhou ${ }^{1}$
}

Published online: 7 October 2015

(C) Springer Science+Business Media New York 2015

Jiao, Cui, Wang, and Xu (2014) developed a ranking of overseas Chines strategy scholars in terms of their contributions to the strategy research. Such a ranking is interesting not only because it provides a clear picture of the academic contributions of overseas Chinese scholars, but also because it can help the universities and scholars in mainland China to develop collaborative ties with overseas Chinese scholars in a more targeted manner.

To complement and extend the work by Jiao et al. (2014), we have adopted a different, but more systematic approach to ranking the overseas Chinese strategy scholars. First, we have generated the list of overseas Chines strategy scholars by checking all of their publications in eight academic journals that are most relevant to the domain of strategy or strategic management. Though this approach is more timeconsuming, it will not miss any potentially important scholars in the analysis. Second, we have focused on the strategy-relevant articles published in the eight academic journals by the overseas Chinese scholars. To that end, we selected only the eight most strategy-relevant journals rather than covering all top-tier business

Weiwen Li

allenliweiwen@gmail.com

Peter Ping Li

ppl.int@cbs.dk

Cheng Shu

novusshu@gmail.com

Meihua Zhou

zhoumh_sysbs@126.com

1 Sun Yat-sen Business School, Sun Yat-sen University, Guangzhou, China

2 Department of International Economics and Management, Copenhagen Business School, Copenhagen, Denmark

3 Henry W. Bloch School of Management, University of Missouri-Kansas City, Kansas City, MO, USA 
journals. In addition, we have coded each article in the selected eight journals to make sure that all articles included in our analysis fall into the broadly defined domain of strategic management. Third, in addition to ranking the listed overseas Chinese scholars based on their strategy research, we have further ranked them based on their Chinarelated strategy publications. Finally and most interestingly, we have applied the method of network analysis to the identification of the co-citation pattern among the listed overseas Chinese scholars

By adopting a more systematic approach to ranking scholars, we have produced ranking results different from those reported by Jiao et al. (2014). Our study complements Jiao et al.'s (2014) study in providing a more complete picture of the academic contributions of overseas Chinese strategy scholars. In this study, we refer overseas Chinese to two groups of individuals. The first group of individuals includes those who were born in mainland China, but now are holding a primary affiliation to nonmainland Chinese institutions. A second group of individuals refers to those who are with the Chinese ancestry, but were born outside of mainland China. According to this definition, overseas Chinese scholars holding a primary affiliation to an institution in Hong Kong, Macao, or Taiwan are also included in our study. Even though Hong Kong and Macau were reunited with China in 1997 and 1999, the Chinese government established Hong Kong and Macau as special administrative regions with a high-degree autonomy. Further, Taiwan is always considered as part of the Greater China region. Finally, a high proportion of the strategy scholars in these three regions had received their degrees from US or European business schools. As a result, the scholarly achievements made by these scholars are similar to those oversea Chinese scholars in Europe and North America.

\section{Research methodology}

\section{Journal selection}

Jiao et al. (2014) chose the top 24 business journals ranked by The University of Texas at Dallas and three additional journals devoted to China and the Asia Pacific region (i.e., Asia Pacific Journal of Management, Management and Organization Review, and Asian Business and Management). Our journal selection is different on two major areas.

First, rather than focusing on all the top 24 leading business journals on the list compiled by the University of Texas at Dallas, we chose only six general management journals (i.e., Academy of Management Journal, Academy of Management Review, Administrative Science Quarterly, Journal of International Business Studies, Organization Science, and Strategic Management Journal). Even though some strategy scholars occasionally publish in journals in various fields other than general management, most tend to publish in general management journals. Since the focus is on strategy research, the selection of all the 24 top journals ranked by The University of Texas at Dallas would distort and obscure the focus on strategy scholars.

Second, we selected only Asia Pacific Journal of Management and Management and Organization Review as the journals devoted to the Asia Pacific region and China, with the deletion of Asian Business and Management. This is primarily because the 
latter has only recently established itself as an SSCI journal of relevance to Asian strategy scholars. According to Journal Citation Report published by Thomson Reuters, the impact factor of Asian Business and Management in year 2014 is .367, while those of Asia Pacific of Journal of Management and Management and Organization Review are 2.742 and 3.277 respectively. Hence, including articles published in Asian Business and Management might produce biased ranking results.

\section{Article selection}

The third major distinction between our approach and that of Jiao et al. (2014) is that we select only a subset of articles which are relevant to our focus on the China-related strategy articles published by the overseas Chinese scholars. Jiao et al. (2014) took into consideration all the articles published in all 24 top journals, but this approach is problematic in the sense that many articles published in the 24 top journals are not strategic in nature (e.g., the articles published in finance and accounting journals, and even some articles in general management journals) or not related to China (this is applicable to all journals).

In this study, we coded each article published in the above-mentioned eight journals in terms of whether an article was strategic in nature. Among the eight journals used to evaluate the strategy scholars, Journal of International Business Studies is an interdisciplinary journal, publishing not only articles on management, but also on accounting, finance, and marketing. In addition, Asia Pacific Journal of Management also occasionally published articles on finance or marketing before 2004. Hence, for the articles published in the above two journals, we first coded whether an article was on management, and then coded it as a strategy article if the level of analysis of the management-related article was organization rather than individual. Other than those two journals, the other six journals only publish management articles. We hence coded the articles published in these six journals as strategy articles based on whether the level of analysis was on organization (either as the primary level or as one of key levels), rather than on individual or team as the primary level.

Finally, we coded whether an article was China-related. Following the procedure of Jia, You, and Du (2012), an article was coded as China-related if (1) part of sample or the full sample was from China, (2) the concepts in the article were developed in the unique Chinese contexts, or (3) the issue or phenomenon examined was unique to the Chinese contexts.

\section{Identification of strategy scholars}

Our approach to identifying the list of strategy scholars also differs from that adopted by Jiao et al. (2014). They generated the list of strategy scholars by identifying those authors who had published articles in Asia Pacific Journal of Management, Management and Organization Review, and Strategic Management Journal, checking the editorial review board members of Management and Organization Review, and searching the registered members of the International Association for Chinese Management Research (IACMR).

Different from the above approach, we identified all the Chinese authors who had published articles in the selected eight management journals. The advantage 
of this approach is that we take into account most of the impactful Chinese authors because most of the core Chinese strategy scholars have published articles in the selected eight journals.

We manually checked each author's background and coded whether he or she was an overseas Chinese. We coded an author as an overseas Chinese if (1) the author was born in mainland China, but received his or her doctoral degree overseas and worked overseas at least for 1 year, or (2) the author was not born in mainland China, but is an ethic Chinese. As a result of this coding procedure, China-born authors who had the overseas educational experience with no or less than 1-year overseas work experiences were not coded as overseas Chinese scholars.

\section{Coding procedures}

In order to ensure that our results are reliable and valid, we triangulated our coding according to the following procedure. First, the authors of this article discussed the coding procedure and developed a coding protocol. Second, we asked two research students to download all the articles published in the eight journals, and then coded the articles and the authors according to the coding protocol independently. Third, the two lead co-authors of this study compared the coding results provided by the research students, and discussed where the two students generated different coding results until the two co-authors reached an agreement on each and every article.

\section{Ranking rules}

Following the procedures adopted by Jiao et al. (2014) and by prior studies on academic ranking (e.g., Lu, 2003; Peng \& Zhou, 2006), we ranked strategy scholars both in terms of the quantity of their contributions (i.e., the number of their articles) and the quality of their contributions (i.e., the citation patterns of their articles). Specifically, we first ranked the overseas Chinese strategy scholars with the measures of raw and adjusted counts of their published articles. For the raw count, we granted each author one full credit per article regardless if he or she is the sole author or one of several coauthors of the article published in the selected eight journals. For the adjusted count, we granted each author the percentage of one-full credit based on the number of co-authors for each article. If an author is the sole author of an article, he or she will be given one adjusted credit. If an author co-authored with one additional author, each of the two coauthors will be given .5 credit (i.e., 1 credit divided by 2 co-authors). Similarly, if an author co-authored an article with two additional authors, each will be given .33 credit (i.e., 1 credit divided by 3 co-authors). This procedure applies to the cases of more than four co-authors. In sum, the credit an author can get from publishing an article is equal to the reciprocal of the number of co-authors for that article.

Second, we also ranked the overseas Chinese strategy scholars with the two measures of the raw and adjusted citations of their published articles. For the raw citation, we calculated the total citations of all the articles published by each author in the selected eight journals. The citations of each article were from Google Scholar on January 18, 2015. For the adjusted citation, given the cumulative nature of citations, we adjusted the absolute citations by the publication year of all articles. An article's adjusted citation equals its Google Scholar 
Citations weighted by $1 /(2012-\mathrm{Y})$ where $Y$ is the year in which the article was published.

It should be noted that, compared with Web of Science SSCI, Google Scholar tends to produce an inflated citation count, since it takes into account working papers and books in addition to journal articles. In contrast, Web of Science SSCI provides a more restrictive citation count based on citations in SSCI listed journals. We chose to base our analyses on Google Scholar because two of our selected journals, Asia Pacific Journal of Management and Management and Organization Review, were not covered by SSCI until 2008. As a result, using Web of Science SSCI citation count might underestimate the impact of scholars who published in these two journals before 2008 .

\section{Research results}

\section{Distributions of articles and authors across eight journals}

Table 1 presents the distributions of strategy articles published by overseas Chinese strategy scholars across the selected eight journals. As shown in Panel A of Table 1, the top three journals in which overseas Chinese strategy scholars published their strategy articles are Journal of International Business Studies, Strategy Management Journal, and Asia Pacific Journal of Management. However, when we consider if those strategy articles are related to China, over

Table 1 Distribution of articles and scholars across eight journals

\begin{tabular}{lrlrl}
\hline \multirow{2}{*}{$\begin{array}{l}\text { Panel A: Distribution of articles across eight journals } \\
\text { Distribution of general strategy articles }\end{array}$} & Distribution of China-related strategy articles \\
Academy of Management Journal & 62 & Academy of Management Journal & 13 \\
Academy of Management Review & 30 & Academy of Management Review & 2 \\
Asia Pacific Journal of Management & 134 & Asia Pacific Journal of Management & 73 \\
Administrative Science Quarterly & 14 & Administrative Science Quarterly & 2 \\
Journal of International Business Studies & 148 & Journal of International Business Studies & 80 \\
Management and Organization Review & 30 & Management and Organization Review & 26 \\
Organization Science & 50 & Organization Science & 9 \\
Strategy Management Journal & 141 & Strategy Management Journal \\
Panel B: Distribution of authors across eight journals & 41 \\
Distribution of authors of general strategy articles & Distribution of authors of China-related strategy articles \\
Academy of Management Journal & 43 & Academy of Management Journal & 9 \\
Academy of Management Review & 22 & Academy of Management Review & 1 \\
Asia Pacific Journal of Management & 106 & Asia Pacific Journal of Management & 63 \\
Administrative Science Quarterly & 11 & Administrative Science Quarterly & 2 \\
Journal of International Business Studies & 103 & Journal of International Business Studies & 56 \\
Management and Organization Review & 26 & Management and Organization Review & 23 \\
Organization Science & 38 & Organization Science \\
Strategy Management Journal & 91 & Strategy Management Journal & 7 \\
\hline & & & 27 \\
\hline
\end{tabular}


$62 \%$ of China-related strategy articles are published in Asia Pacific Journal of Management and Journal of International Business Studies.

Panel B of Table 1 presents the distribution of authors of strategy articles across journals. We found that 105 overseas Chinese strategy scholars had published strategy articles in Asia Pacific Journal of Management, while 102 overseas Chinese strategy scholars had published their strategy articles in Journal of International Business Studies. The distribution of authors of China-related strategy articles shows a similar pattern.

\section{Ranking overseas Chinese scholars based on strategy articles}

Table 2 shows the rankings of overseas Chinese scholars based on both the quantity and quality of their contributions. Given the space limitation, we only report the top 40 scholars according to their adjusted article counts and adjusted citations. Because we took into account only the articles from the eight journals (instead of 27 journals) and we excluded those articles that were unrelated to strategy (instead of having both strategy and non-strategy articles), the raw count, adjusted count, raw citations, and adjusted citations for some scholars reported in our tables are different from those reported by Jiao et al. (2014).

Several notable differences between our ranking results and those reported by Jiao et al. (2014) are worth mentioning. First, several authors with high ranking in terms of both quantity and quality of contributions were not included in the study by Jiao et al. (2014). For example, Jiatao Li, Wenping Tsai, Chung-Ming Lau, Kevin Zheng Zhou, and Phillip H. Phan had relatively high rankings in terms of quality of contributions, but they were missing in the reported ranking by Jiao et al. (2014). The primary reason for this difference is that Jiao et al. (2014) did not include those Chinese scholars who worked in Hong Kong, Macao, and Taiwan in their study, but we did cover them. The policies of the Chinese government to attract established overseas scholars also apply to those who work in Hong Kong, Macao, and Taiwan. For example, taking advantage of the policies issued by the Ministry of Education in China, Kevin Zheng Zhou became a "Changjiang Scholar" Chair Professor at Xi'an Jiaotong University in early 2015. In addition, since such scholars are working in Hong Kong, Macao, and Taiwan, they are geographically closer to the universities in mainland China relative to those who work at the universities in the US and Europe. It is worth noting that the Chinese scholars based in East Asia as a group tend to rank higher in terms of China-related publications. This may be due to the easier access to the data in mainland China and more convenient for them to build close collaborative relationships with more scholars based in mainland China.

Another reason that some of the top-notch Chinese scholars were missing in the study by Jiao et al. (2014) is that, although they were trying to build a comprehensive list of overseas Chinese strategy scholars, their approaches of identifying such scholars tend to miss some scholars. As mentioned earlier, Jiao et al. (2014) first compiled a list of authors who had published articles in Asia Pacific Journal of Management, Management and Organization Review, and Strategic Management Journal, plus the members of the editorial review board of Management and Organization Review, and the registered members of the IACMR. However, it is still highly likely that some overseas Chinese scholars 


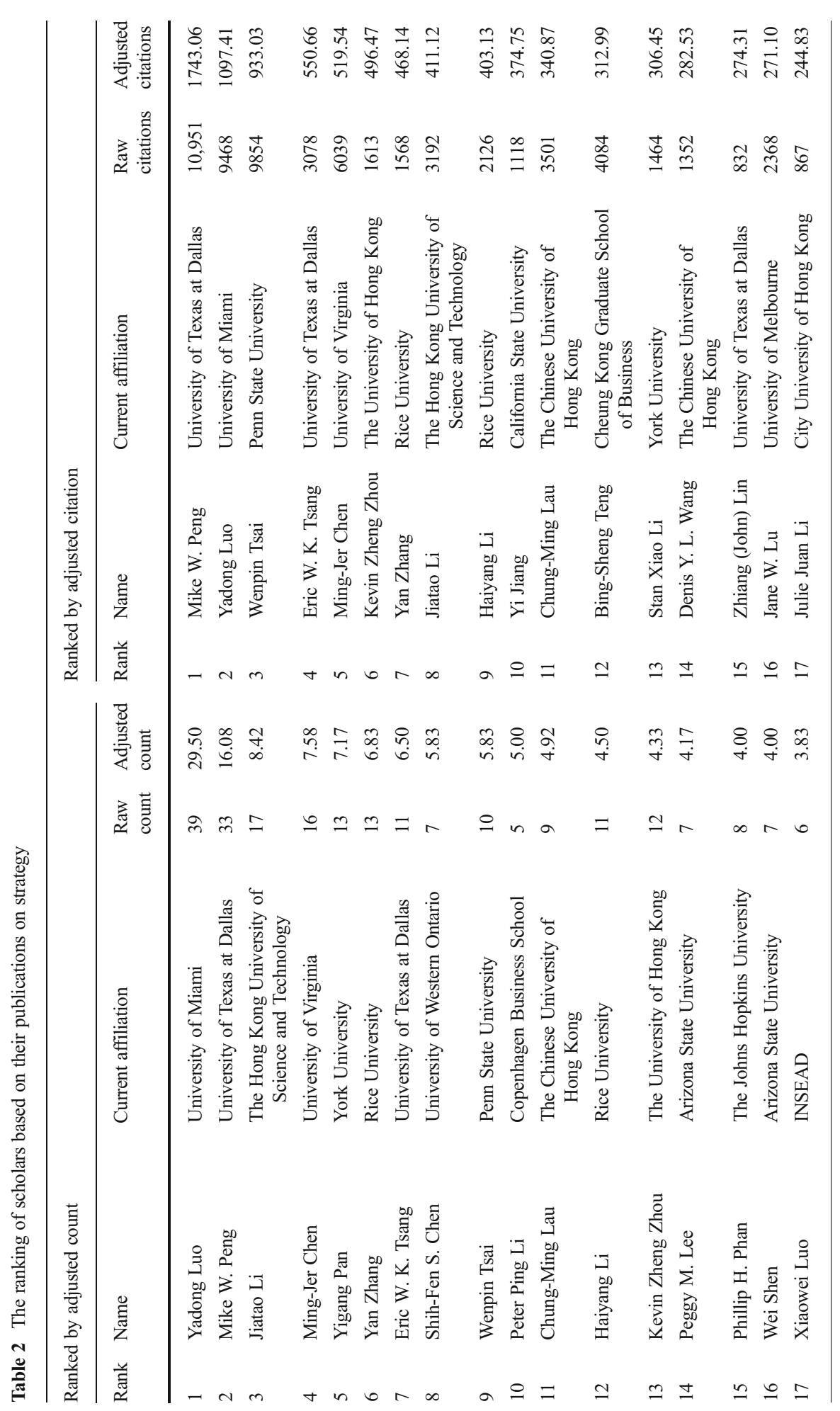




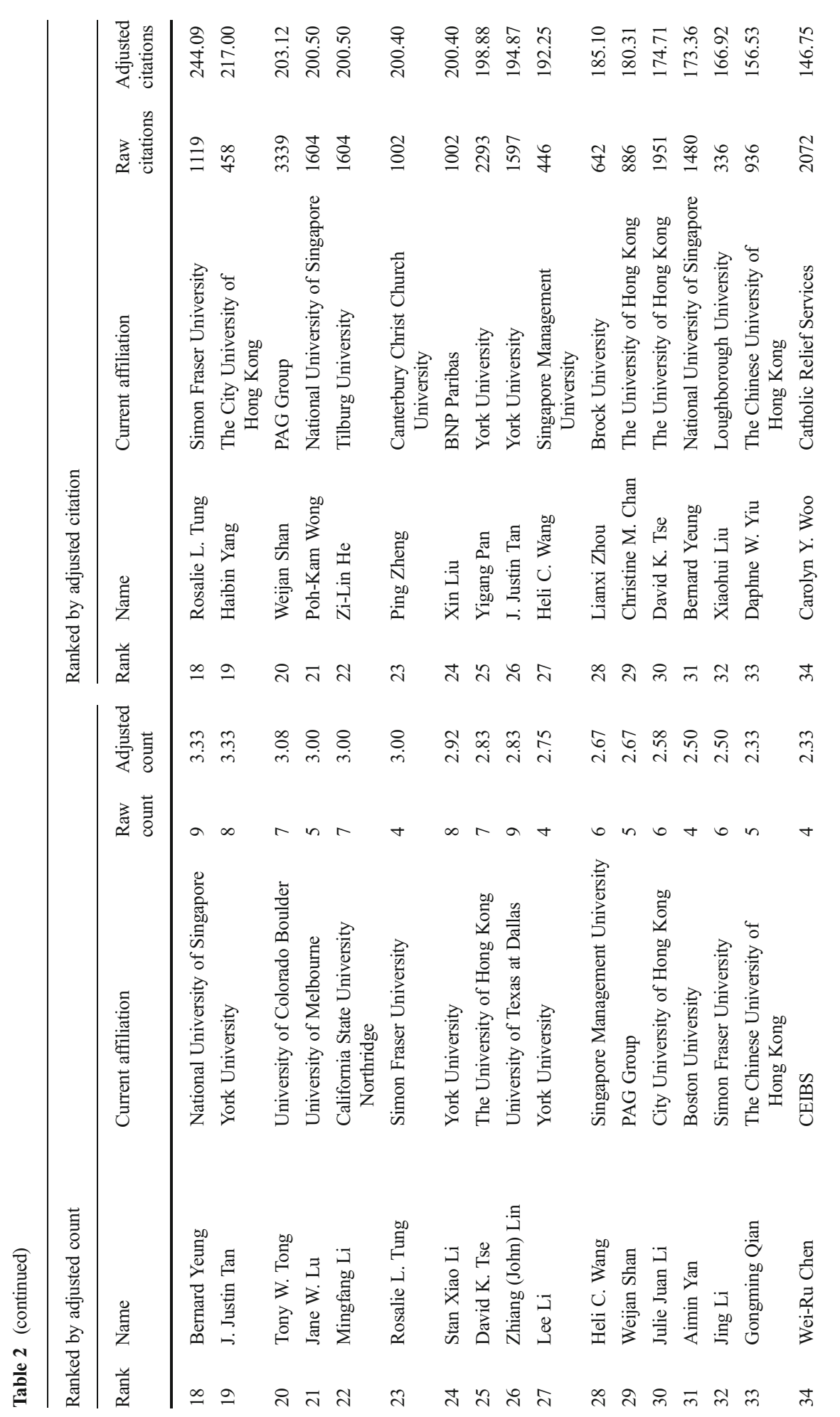




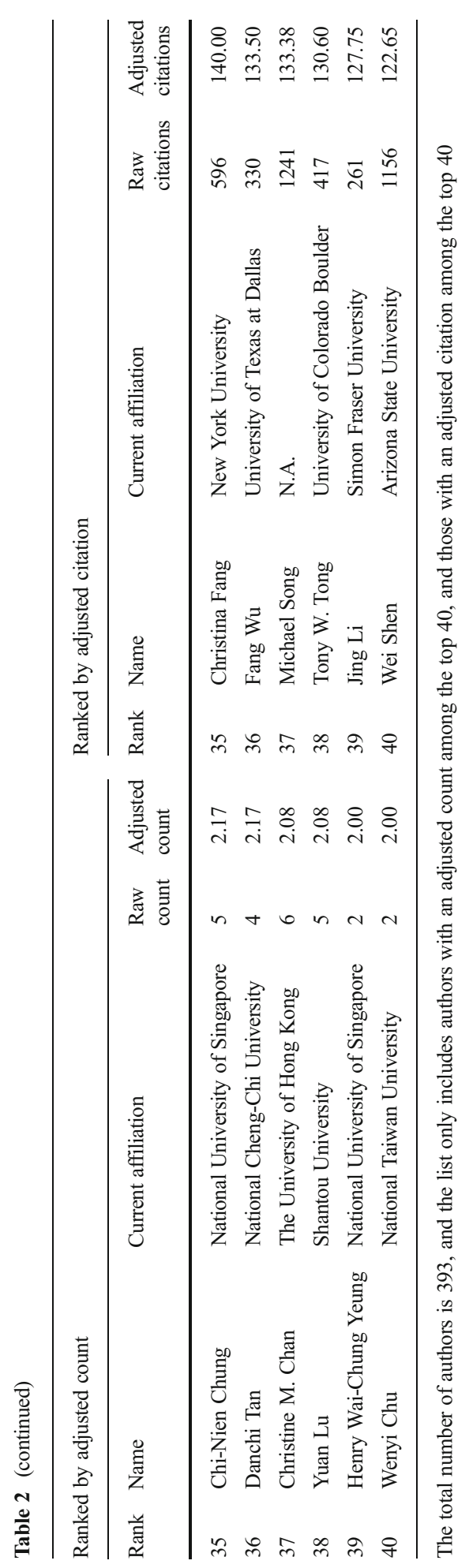


may not have published in the above three journals, nor had they joined the IACMR and been selected as the editorial members of Management and Organization Review. As a matter of fact, Jiao et al. (2014) only identified 151 overseas Chinese strategy scholars. In contrast, we used a different approach: we checked all the published articles in the selected eight journals, and we actually identified 393 overseas Chinese strategy scholars, almost doubling the number of authors identified by Jiao et al. (2014).

A second difference between our results and those of Jiao et al. (2014) is that, although our selection of journals is more restrictive and the eight journals we selected are all covered in their study (thus the raw count for an author in our study should be lower than or equal to that reported by Jiao et al.), we even identified more publications for one author in our list (i.e., Shih-Fen Chen). We wondered that the reason might be that, because they generated the name list first and used the name list to search their journal publications, they might have missed some of the publications when different journals used different ways to list author names. For example, we found that while the name of Shih-Fen Chen appeared at Journal of International Business Studies as "Chen, Shih-Fen S.," it appeared in Strategic Management Journal as "Shih-Fen S. Chen," and in Asia Pacific Journal of Management as "Shih-Fen Chen."

Third, because of the different approaches used to identify the articles and authors, our rankings of overseas Chinese strategy scholars also differs from those reported by Jiao et al. (2014). Notably, Jiatao Li, Shif-Fen Chen, and Wenpin Tsai are ranked as 3rd, 8th, and 9th in terms of quality of contributions. As mentioned earlier, Jiatao Li was not included in the study by Jiao et al. (2014) since he worked at a Hong Kong university, while Shif-Fen Chen was not ranked among the top 10 scholars due to the fact that the study by Jiao et al. (2014) missed some of his publications when they searched his name in the databases. In addition, Wenpin Tsai was not in the list of top 34 authors in the study by Jiao et al. (2014) both in terms of quantity and quality of contributions. Hence, it is highly likely that Jiao et al. (2014) had missed Wenpin Tsai when they generated the name list for overseas Chinese strategy scholars. This again shows the limitations of the approach adopted by Jiao et al. (2014).

Our results also differ from those reported by Jiao et al. (2014) in the ranking of authors in terms of quality of contributions. In particular, in the ranking of authors' quality of contributions, Wenpin Tsai, Kevin Zheng Zhou, and Jiatao Li were ranked as 3rd, 6th, and 8th, respectively. As mentioned above, all three authors were missing in the study by Jiao et al. (2014) because Kevin Zheng Zhou and Jiatao Li were working at Hong Kong universities, while Wenpin Tsai was not included possibly due to the approach by Jiao et al. (2014) in generating the name list.

In addition, Michael Song was listed as a top 10 scholar both in terms of quantity and quality of contributions in the study by Jiao et al. (2014), while in our study he is ranked as 37 th according to the adjusted citation. The major reason for this difference is that Michael Song has a marketing background and has published many articles in top-tiered marketing journals (e.g., Journal of Marketing and Journal of Marketing Research) that are among the top 24 business journals listed by The University of Texas at Dallas. In contrast, because we have 
taken into account only general management journals, we have excluded Michael Song's publications in marketing journals from our analyses.

\section{Ranking of overseas Chinese strategy scholars based on China-related articles}

As mentioned earlier, the purpose of Chinese state policies is to encourage collaborations between overseas Chinese scholars and mainland Chinese scholars. We expect that those who engage in China-related research should have shared interests in collaboration, especially between overseas Chinese scholars and mainland Chinese scholars. For this reason, it might also be helpful for the Chinese government agencies and universities to be able to identify those overseas Chinese scholars who are most actively involved in China-related research.

Table 3 presents the ranking of overseas Chinese scholars based on their Chinarelated strategy publications. There are several notable differences between Tables 2 and 3 in terms of the rankings of both quantity and quality of contributions. First, in terms of quantity of contributions, while only one scholar based at a university in Hong Kong was ranked at the top 10 in Table 2, there are four scholars from the universities in Hong Kong were ranked at the top 10 in Table 3 (i.e., Jiatao Li, Kevin Zheng Zhou, Julie Juan Li, and David K. Tse).

Similarly, Chung-Ming Lau and Denis Y. L. Wang, both of who are working in Hong Kong, are ranked as the 5th and 10th in terms of quality of contributions in Table 3, but they are not at the top 10 in Table 2. These differences again provide evidence that the scholars who work at the universities in Hong Kong are more likely to have the stronger interest in doing China-related research. Hence, in order to truly promote the collaboration between mainland Chinese scholars and overseas Chinese scholars, we should take into account overseas scholars who work in Hong Kong, especially for China-related research.

Further, another difference between Table 2 and Table 3 is that Haiyang Li and J. Justin Tan are ranked as top 10 scholars concerning quantity of contributions in Table 3. Indeed, nine out of 11 strategy articles published by Haiyang Li, and seven out of eight strategy articles published by J. Justin Tan are China-related. Hence, when seeking collaborative relationship with overseas scholars, mainland Chinese universities and scholars need to pay attention to not only overseas scholars' quantity of publication, but also their specific areas of interest and expertise, especially those China-related ones.

\section{Rankings based on China-related strategy articles across different journals}

Publishing in the top six general management journals (i.e., Academy of Management Journal, Academy of Management Review, Administrative Science Quarterly, Journal of International Business Studies, Organization Science, and Strategic Management Journal) can be much more difficult than publishing in Asia Pacific Journal of Management and Management and Organization Review. However, largely because Asia Pacific Journal of Management and Management and Organization Review have the missions of publishing studies devoted to the Asia Pacific and China, the two journals are much more receptive to China-related strategy articles. As a result, we have further ranked overseas Chinese strategy scholars based on their China-related strategy 


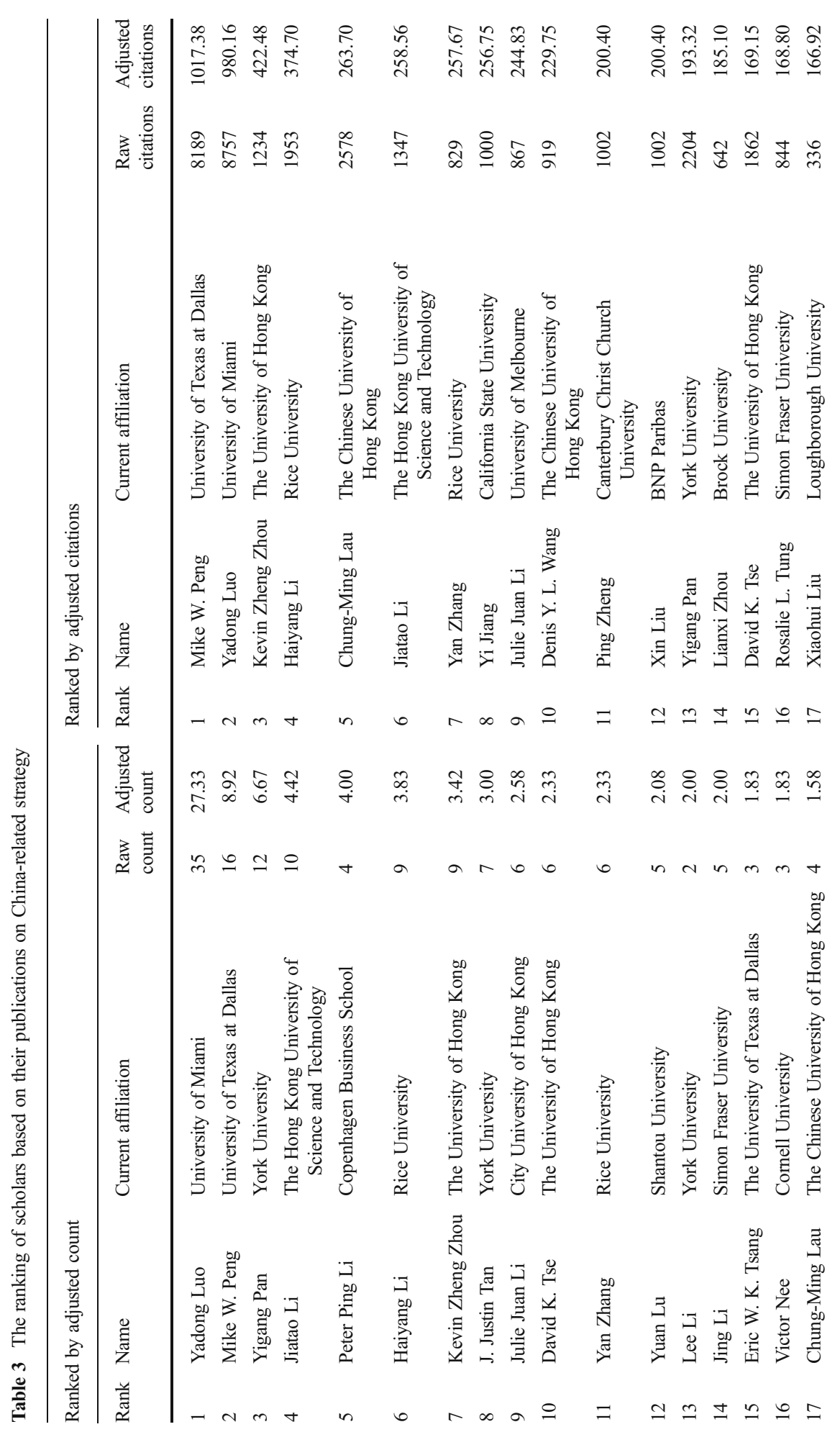




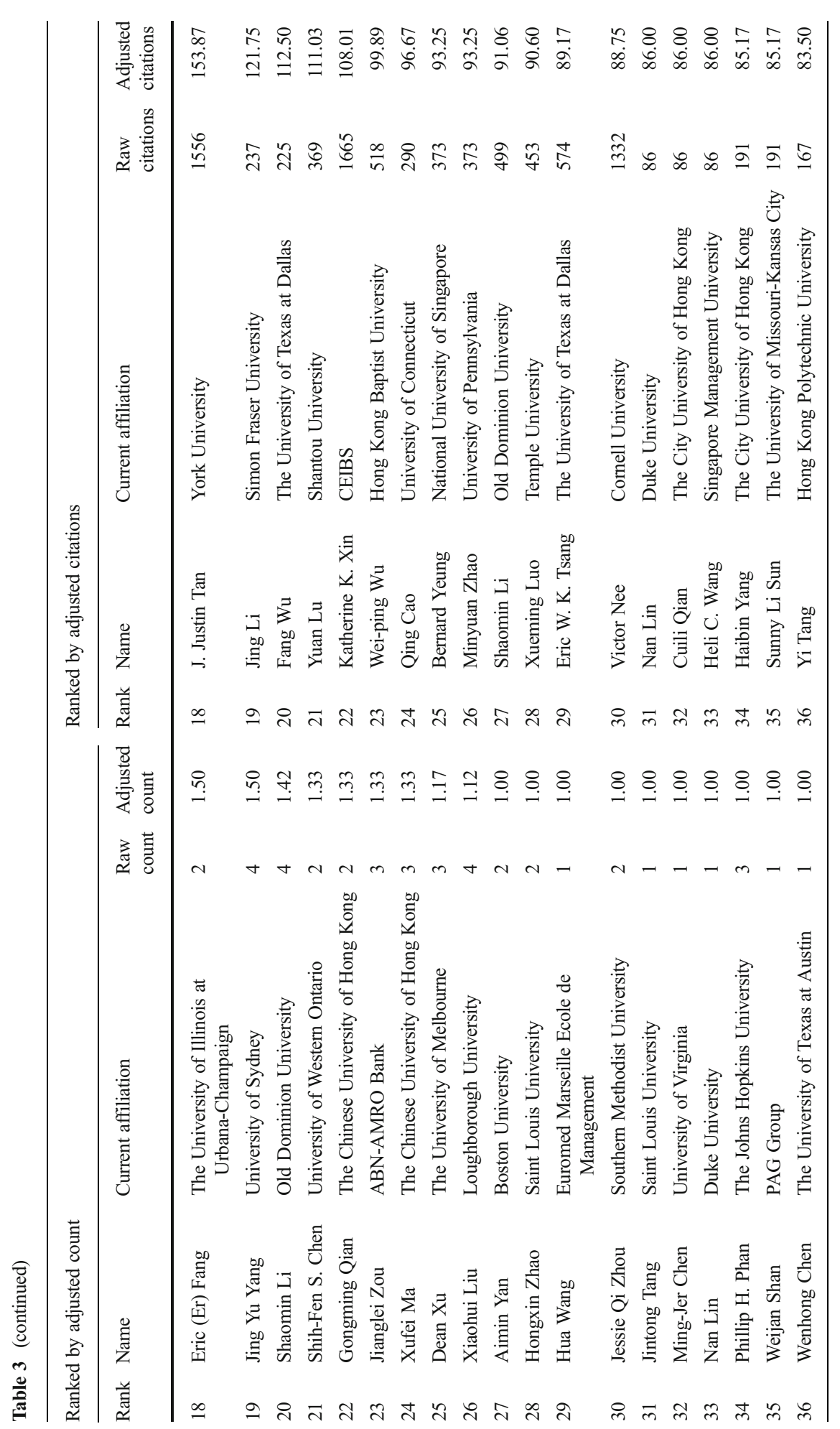




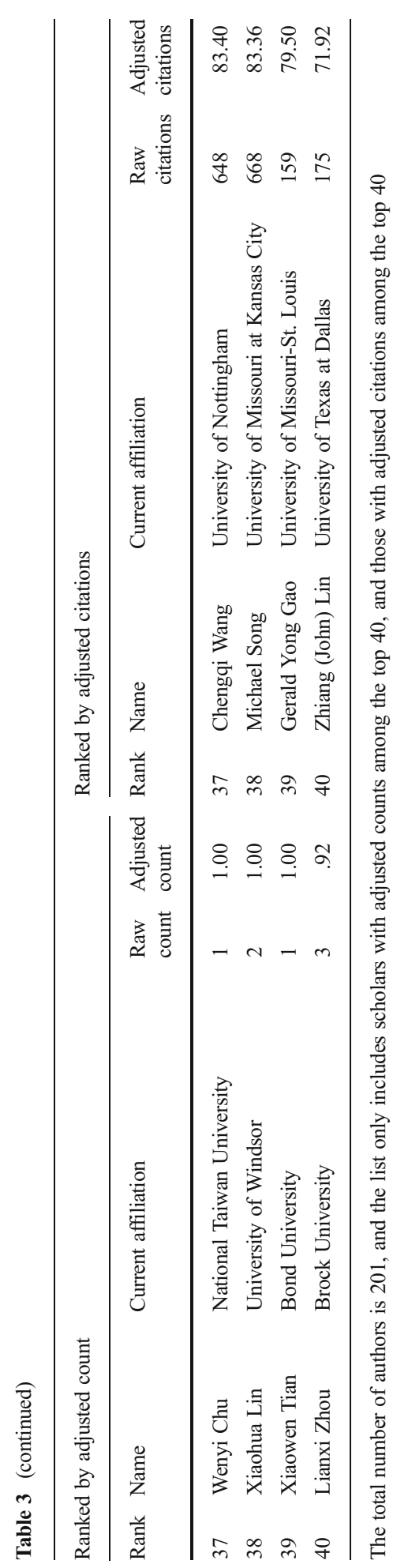




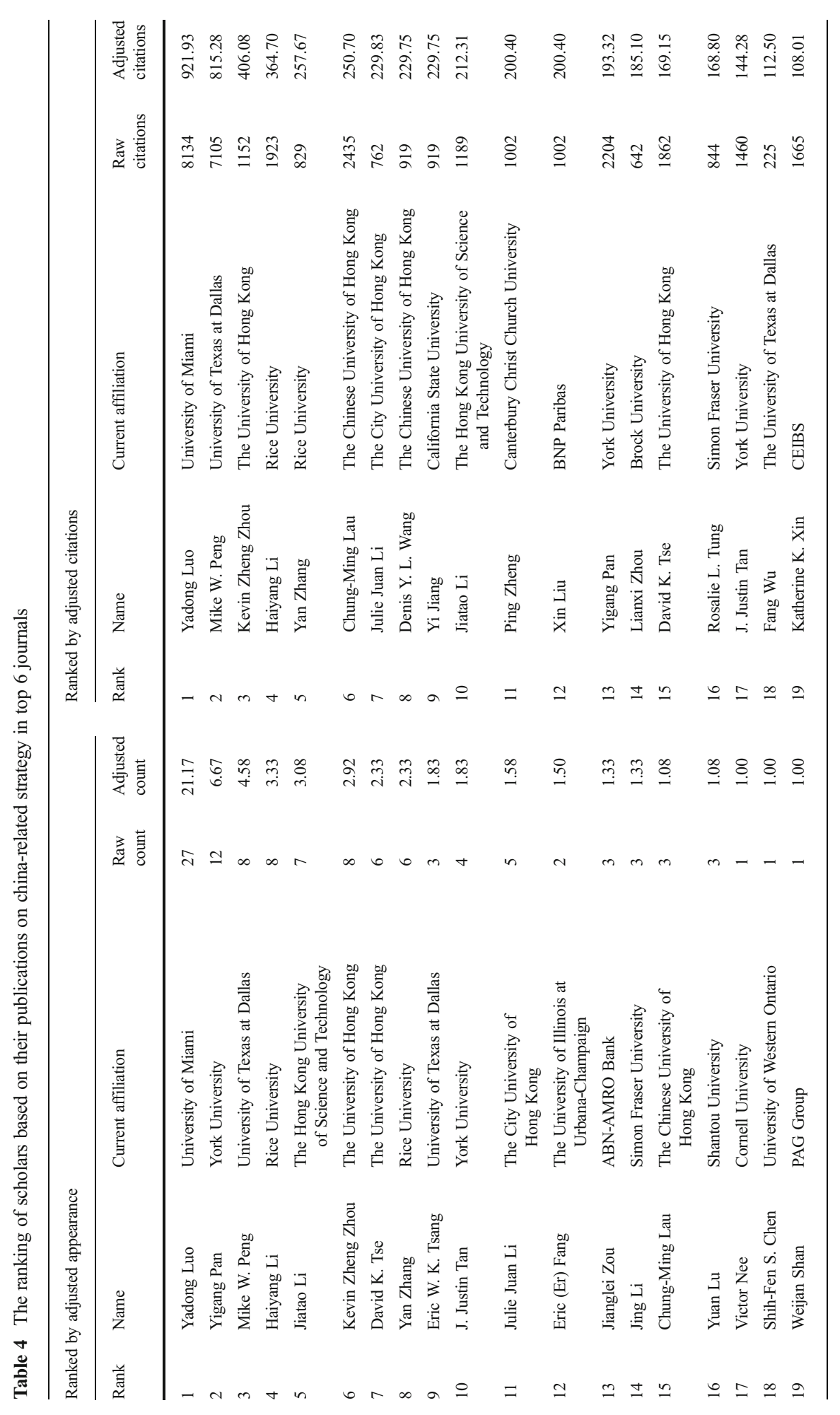




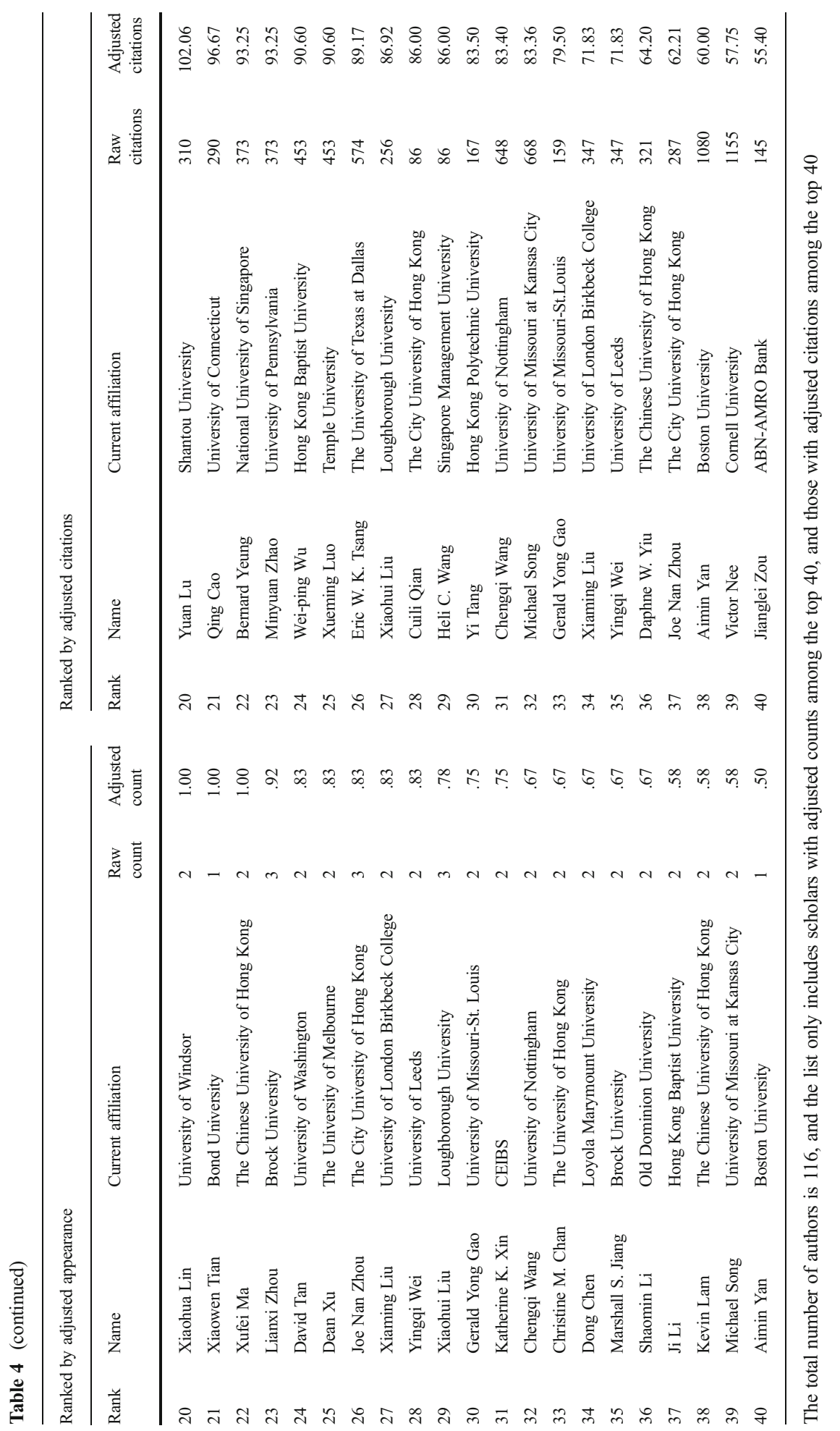


publications in the top six journals and in the two journals devoted to the Asia Pacific and China, respectively.

Table 4 presents the rankings of overseas Chinese strategy scholars according to their China-related strategy articles in the top six journals. These results are similar to those reported in Table 3, with only a few changes in their rankings as measured by both the quantity and quality of their contributions.

Table 5 presents the ranking of overseas Chinese strategy scholars according to their China-related strategy articles in Asia Pacific Journal of Management and Management and Organization Review. There are several notable features in terms of the ranking results in Table 5. First, though Yadong Luo and Mike W. Peng remained as the most prolific scholars, Peter Ping Li was ranked as the 3rd in terms of the quantity of contribution. Second, Nan Lin, Xiaohui Liu, and Jing Li were ranked as the 2nd, 3rd, and 4th in terms of quality of contribution in Table 5. In particular, although both Nan Lin and Xiaohui Liu only has one article published in Management and Organization Review in year 2011, their articles were highly cited over 80 times in subsequent years.

\section{Discussion}

\section{Critical implications}

We have ranked overseas Chinese strategy scholars via an approach different from that of Jiao et al. (2014). We have obtained some interesting ranking results distinctive from those reported by Jiao et al. (2014). Consequently, our study makes several unique contributions. First, we have suggested and provided evidence that by checking all the published articles one by one could generate a more comprehensive list of authors for ranking scholars in terms of their contributions. Indeed, though using the list of editorial review board members (e.g., Management and Organization Review) as well as the members of academic associations (e.g., IACMR) can be helpful in identifying relevant scholars, relying too much on such lists can miss some important scholars, thus leading to some biased results. Hence, future studies concerning the ranking of academic contributions need to rely on the more time-consuming approach of checking all published articles for more reliable ranking data.

Second, our results also reveal the importance of including scholars from Hong Kong in the ranking of overseas Chinese scholars. As the ranking results in this study show, overseas scholars from Hong Kong have been making important academic contributions in terms of both quantity and quality of contribution. In particular, these authors tend to have the stronger interest in engaging in China-related research than those from the US and Europe. For this reason, if Chinese government intends to promote effective collaboration between mainland Chinese scholars and overseas Chinese scholars, it should pay more attention to those scholars who are based at the universities in Hong Kong.

Third, our rankings results based on China-related strategy research show that overseas Chinese scholars might not necessary conduct China-related research. Indeed, because most of these scholars received their doctoral degrees from US or European universities, it is highly likely that a great proportion of them might 


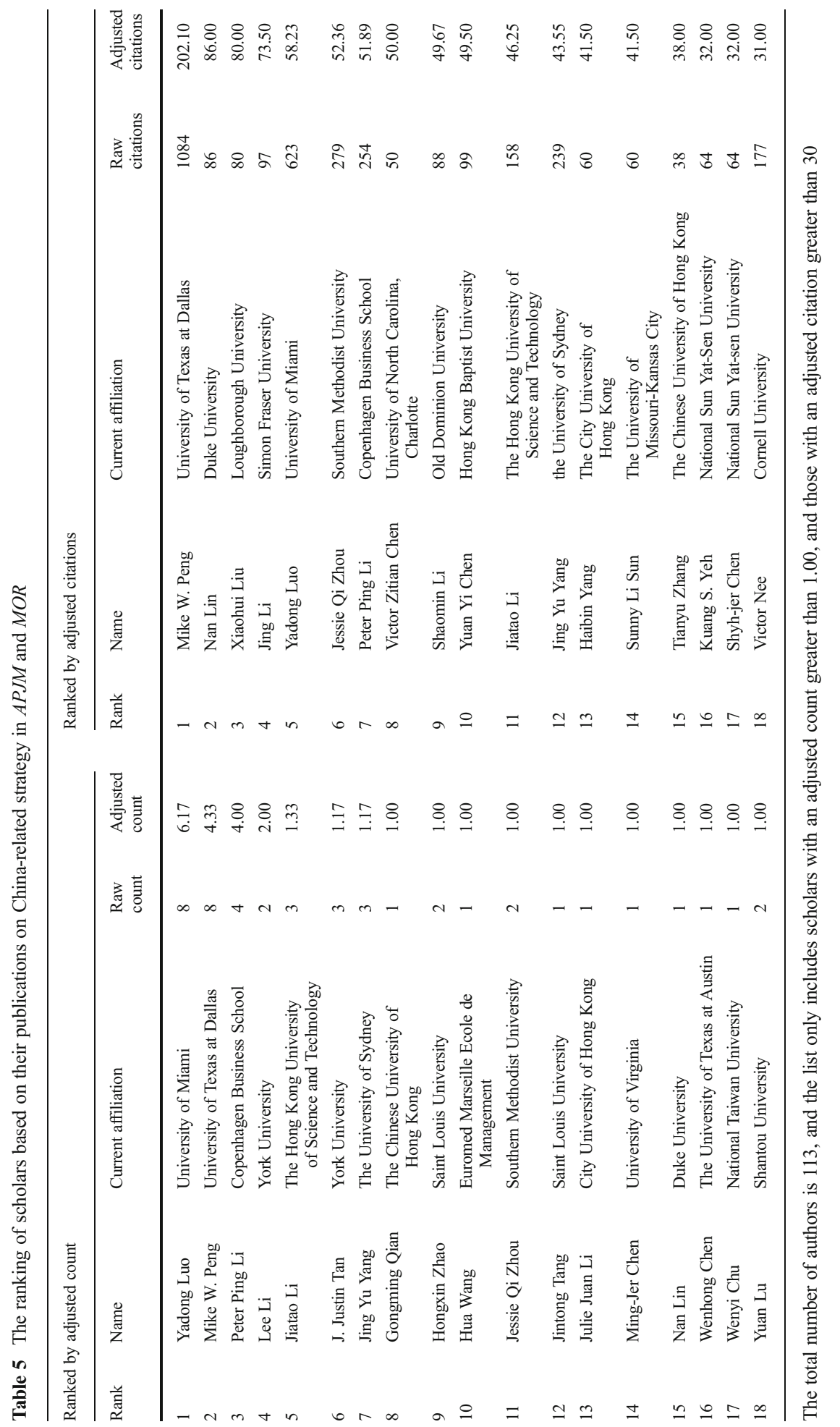


choose to do research that is more relevant to US or European companies. In this sense, differentiating China-related studies from those studies that have nothing to do with China can further help the Chinese government to target relevant overseas scholars in a more effective way.

\section{Additional co-citation analysis}

To further understand how overseas Chinese strategy scholars interact and interconnect with each other, we conducted author co-citation analysis to reveal the intellectual structure among overseas Chinese strategy scholars at different periods of time. A cocitation count is the frequency with which two references or authors are cited together by the later literature (Small, 1973). In our study, a co-citation count between two given authors can result from citing two articles written by them separately and citing one coauthored article. Co-citation analysis has been widely used in various disciplines, including management (e.g., Nerur, Rasheed, \& Natarajan, 2008; Ramos-Rodríguez \& Ruíz-Navarro, 2004), and it has been considered a reasonable measure of the proximity among, and influence of, the cited authors (McCain, 1990; Mullins, Hargens, Hecht, \& Kick, 1977).

The co-citation analysis in this study has been conducted on two lists of authors. The first was the top 40 overseas Chinese strategy scholars ranked by their strategy articles (Table 2, adjusted count rank). The second list was the top 40 overseas Chinese strategy scholars ranked by their China-related strategy articles (Table 3, adjusted count rank). We treated each author as a collection of all his or her publications and citations, and divided the related data into three periods: Period 1 (before 2000), Period 2 (20012007), and Period 3 (2008-2014) to track the possible temporal patterns of evolution.

The technical procedure to generate the co-citation network graphs is as follows. First, we retrieved all relevant citation information to all articles in the selected eight journals by each of the top 40 authors from the Web of Science SSCI based on cited reference search. Second, we generated the raw counts of co-citations among every pair of authors into a matrix. Third, the raw count matrix was converted into a social network file and then imported to the social network analysis software (SNA) of Gephi (Bastian, Heymann, \& Jacomy, 2009). Finally we presented the visualized network map using the build-in algorithm of "ForceAtlas" (for details of this algorithm, see Noack, 2007).

Figures 1, 2, and 3 display the network diagrams in three periods of the top 40 overseas Chinese scholars in Table 2. Figures 4, 5, and 6 display the network diagrams in three periods of the top 40 overseas Chinese scholars in Table 3, based on their Chinese-related articles. In each network graph, each scholar is represented by a circle, and the size of the circle is proportional to the raw count of the scholar's publications in the selected eight journals. The color pattern is based on the centrality of each scholar: the darker the color, the higher the centrality. The thickness of the curved lines among the scholars is proportional to their co-citation count. In order to improve readability, co-citation counts at different periods are normalized differently, so comparing circle sizes or line thicknesses across different graphs across the three periods is not meaningful.

In our brief analysis, we focus primarily on the centrality of individual authors and also the general trend of community development. In co-citation analysis, it is 


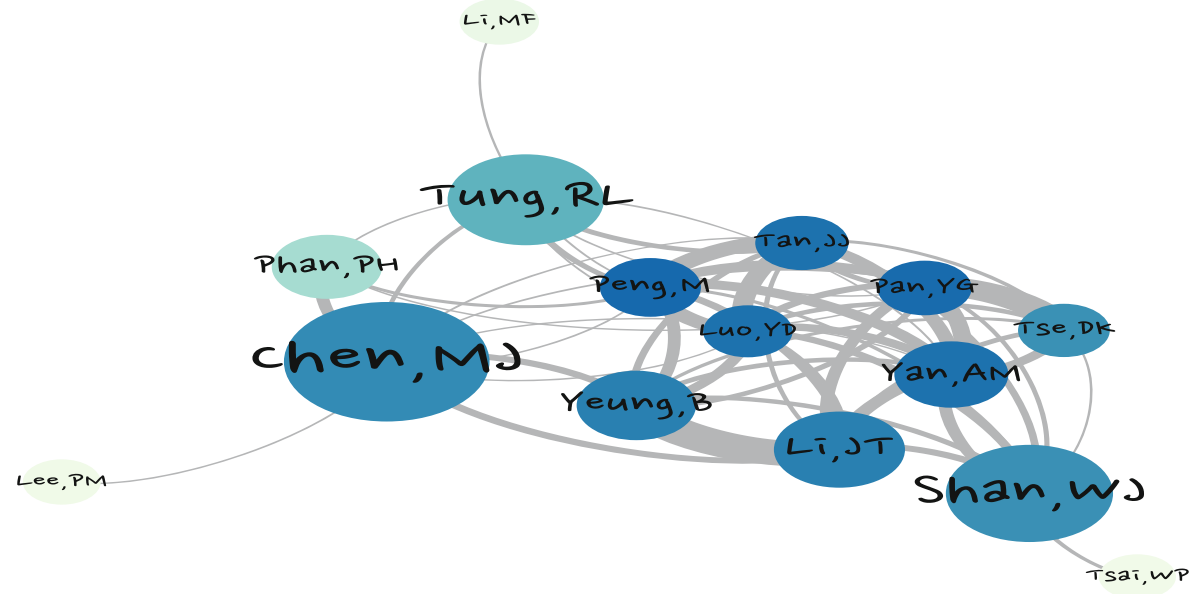

Fig. 1 Network diagram of scholars in Table 2 by adjusted count rank (Before 2000)

common to see the citation to a certain article starts to grow only 6-10 years after its publication. This is because it tends to take some years for other articles that cite the prior article to get published, so an article cannot get cited at the time of its publication. In our database, the majority of articles were published after the year of 2000, so the influence of the Chinese scholars as a whole was quite small before 2000: only the publications of a handful scholars were cited by peers, as shown in Figs. 1 and 4.

In later two periods, the graphs (Figs. 2, 3, 4, 5, and 6) show a growing trend of strategy research regarding the two domains of general strategy research and China-related strategy research. The center position of Yadong Luo and Mike W. Peng is more prominent during these years in both domains of research. This finding is in accordance with the non-graph ranking results. It shows that not only are the two author most prolific, but also they are at the center of research community network. Even though Ming-Jer Chen maintains his influence across

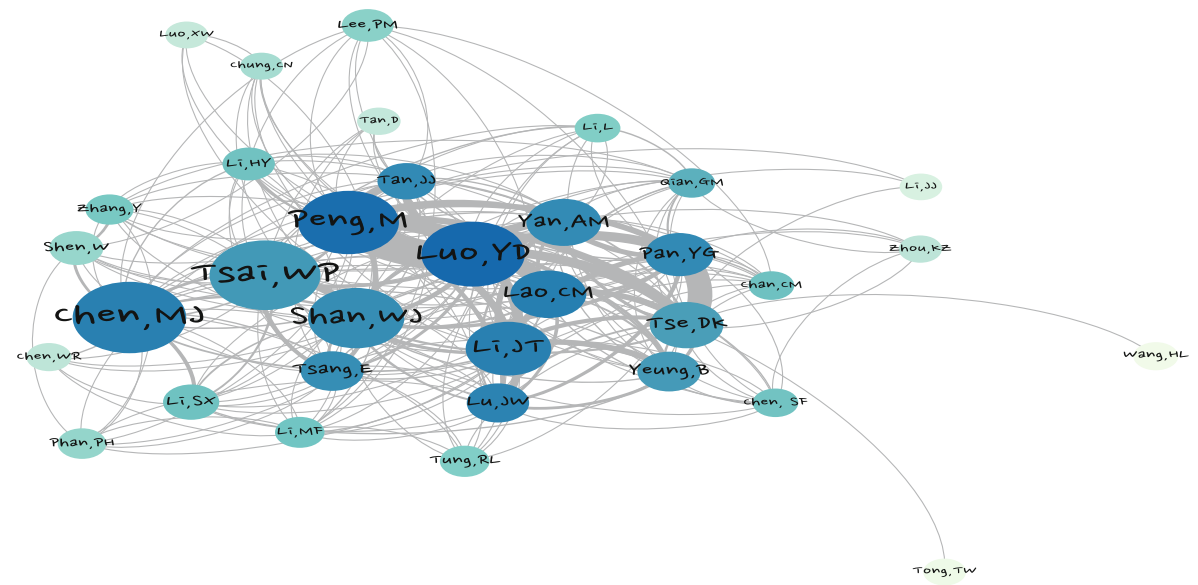

Fig. 2 Network diagram of scholars in Table 2 by adjusted count rank (2001-2007) 


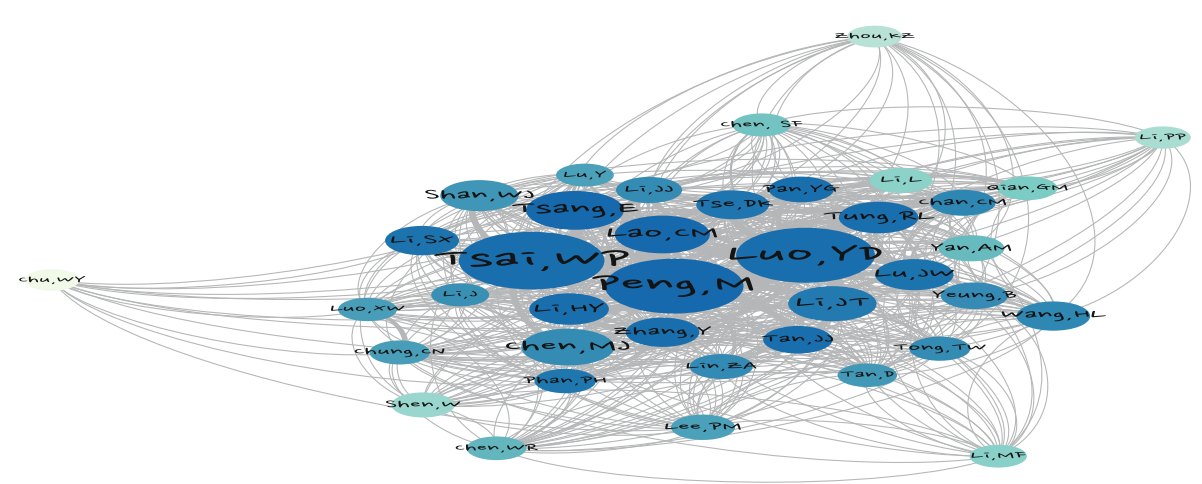

Fig. 3 Network diagram of scholars in Table 2 by adjusted count rank (2008-2014)

all three periods, the research community displays a diverging trend of interest in the later periods, so his more recent position has become a more localized center later. Further, several factors can contribute to the centrality of an author. Besides an author's large number of publications, citations, and co-citations, centrality can also reflect the author's broad interest in various topics. The broader the interest in more topics with diverse publications, the more centralized he or she may become, ceteris paribus.

Also related to the non-graph ranking results in Table 2, high-ranking scholars, such as Eric Tsang, Wenping Tsai, Jiatao Li, Chung-Ming Lau, and Rosalie L. Tung also occupy positions close to the center in Periods 2 and 3 (Figs. 2 and 3). In particular, Wenping Tsai's influence kept rising and reached a critical position in the most recent period (Fig. 3). Similarly, many high-ranking scholars in Table 3, such as Yigang Pan, Chung-Ming Lau, Eric Tsang, Haiyang Li, Jiatao Li, and Yan Zhang locate also close to the center in Periods 2 and 3 (Figs. 5 and 6).

Finally, scholars from Hong Kong form a considerable part of the total network, but they do not all cluster together. This also reflects their divergent interests in the domain of

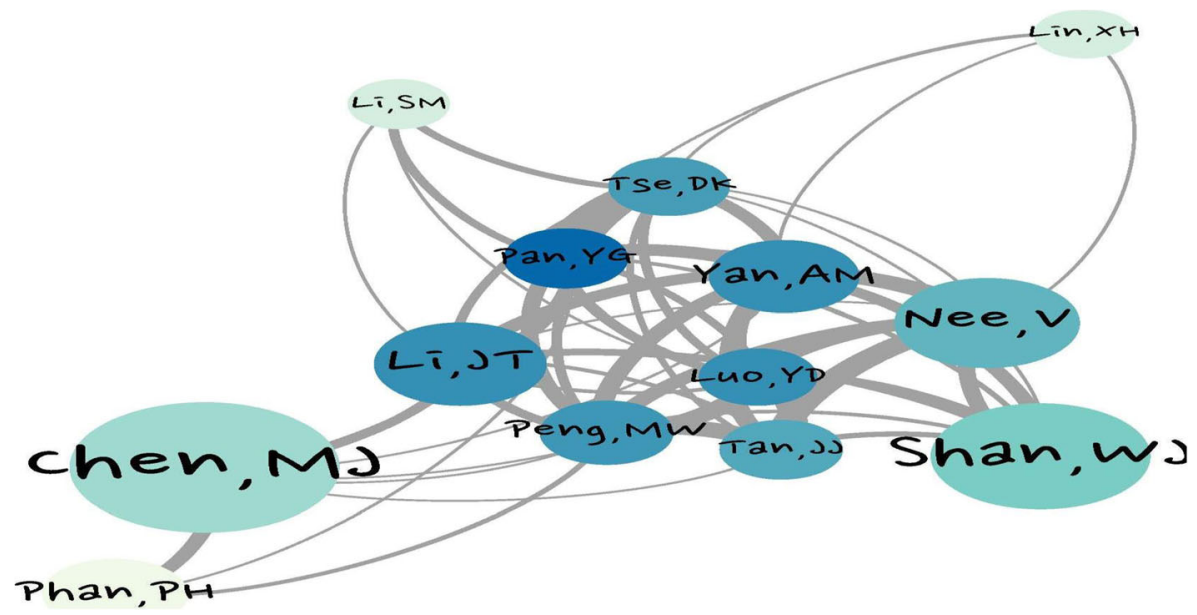

Fig. 4 Network diagram of scholars in Table 3 by adjusted count rank (Before 2000) 


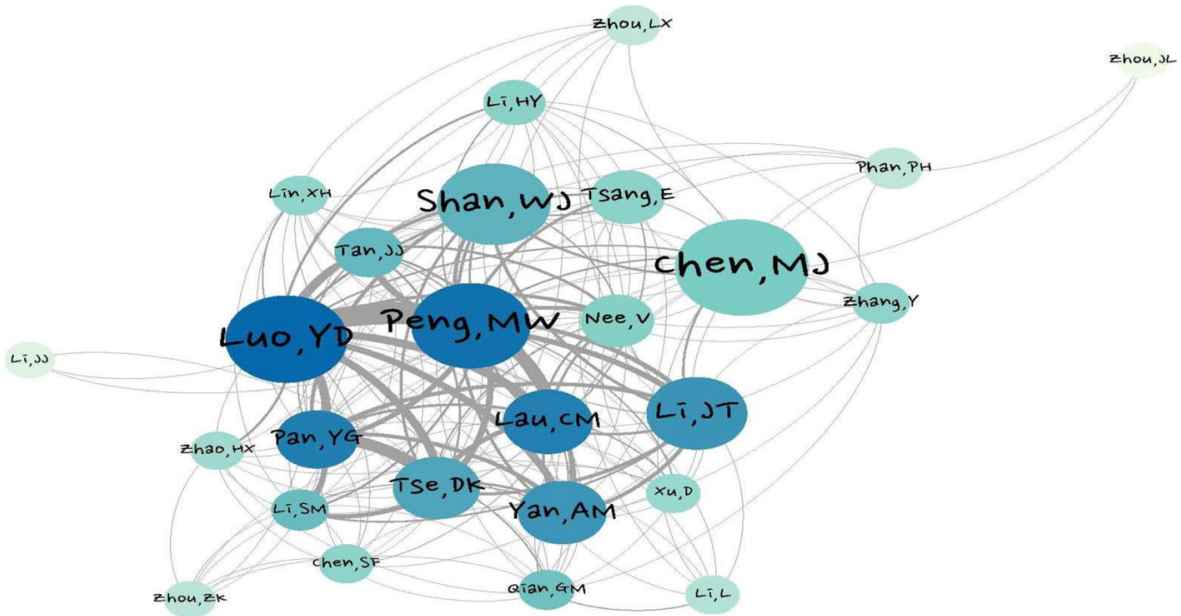

Fig. 5 Network diagram of scholars in Table 3 by adjusted count rank (2001-2007)

strategy research (including China-related and non-China-related), and their extensive collaborations with other overseas Chinese scholars across the world beyond Hong Kong.

One special note is worth mentioning. Among the eight journals we selected, SSCI only covers Asia Pacific Journal of Management and Management and Organization Review from 2008 onward, so those scholars who published in these two journals before 2008 are under-presented in all the co-citation graphs.

\section{Limitations and future research directions}

Some limitations of this study should be acknowledged. First, although we selected the eight journals based on relevance and quality, we cannot rule out the possibility that some overseas Chinese overseas scholars might choose to publish in other journals that are not in our list. For example, some scholars might have published their articles in

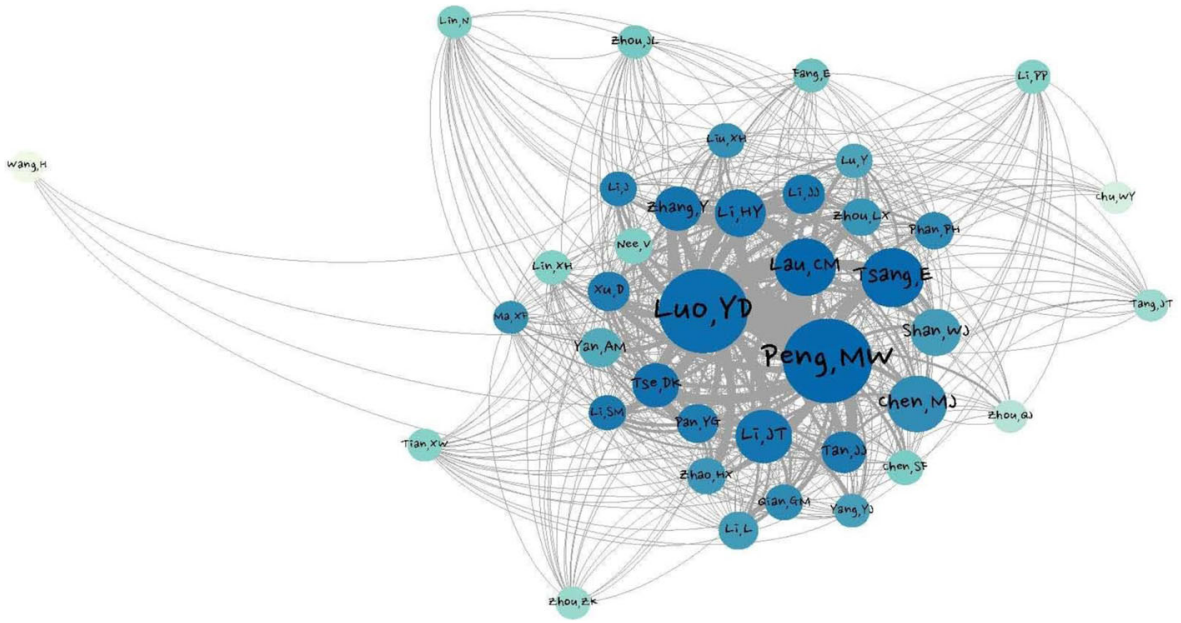

Fig. 6 Network diagram of scholars in Table 3 by adjusted count rank (2008-2014) 
high quality journals, such as Journal of Management Studies and Journal of Management. This might bias our ranking results. Hence, future studies can expand the journal list so as to develop a broader dataset for the purpose of ranking overseas Chinese scholars.

Second, we focus simply on studies on strategy, to the exclusion of studies on other topics. Since the Chinese government is trying to attract overseas scholars from a variety of fields of study, future study can also benefit by developing the rankings of scholars based on their publications on other domains, such as organizational behavior, marketing, finance, accounting, and operational management.

Third, the co-citation analysis does not focus on the topical issues beyond taking all the publications of each scholar so as to reveal where specifically each scholar is most influential. Future research can focus on the issue of topical interconnections to show how scholars are interacting and mutually influencing each other in special topical areas rather than the overall influence of such scholars without specifying where their primary impacts lie.

\section{Conclusion}

By checking the published articles in the selected list of eight most relevant journals, this study provides a systematic and relevant ranking and mapping of overseas Chinese strategy scholars. Based on multiple ranking and mapping methods, Yadong Luo and Mike W. Peng are found to be the most impactful scholars in both terms of quantity and quality of contributions. Further, our ranking and mapping results reveal that overseas Chinese strategy scholars working at the universities in Hong Kong are as prolific as those working in the US and European universities. Our ranking and mapping analysis can provide useful information for mainland Chinese universities and scholars to identify research collaborators among overseas Chinese strategy scholars, especially in the area of China-related strategy research. Finally, we call for more attention to China-related strategy research because it is the unique domain where the special competitive advantages of Chinese strategy scholars would lie.

Acknowledgments We are grateful to APJM editor Michael Carney for his constructive and detailed comments on previous versions of our article. We also thank the support provided by the National Natural Science Foundation of China (Grant Numbers 71202095, 71572198, 71232009, and 71332004) and the Guangdong Planning Office of Philosophy and Social Science Program (Grant Number GD14XGL13).

\section{References}

Bastian, M., Heymann, S., \& Jacomy, M. 2009. Gephi: An open source software for exploring and manipulating networks. International AAAI Conference on Weblogs and Social Media.

Jia, L., You, S., \& Du, Y. 2012. Chinese context and theoretical contributions to management and organization Research: A three-decade review. Management and Organization Review, 8(1): 173-209.

Jiao, H., Cui, Y., Wang, Q., \& Xu, S. 2014. High impact strategy research by overseas Chinese scholars in leading business journals: 1991-2011. Asia Pacific Journal of Management. doi:10.1007/s10490-0149392-x. 
Lu, J. W. 2003. The evolving contributions in international strategic management research. Journal of International Management, 9(2): 193-213.

McCain, K. W. 1990. Mapping authors in intellectual space: A technical overview. Journal of the American Society for Information Science, 41(6): 433-443.

Mullins, N. C., Hargens, L. L., Hecht, P. K., \& Kick, E. L. 1977. The group structure of cocitation clusters: A comparative study. American Sociological Review, 42(4): 552-562.

Nerur, S. P., Rasheed, A. A., \& Natarajan, V. 2008. The intellectual structure of the strategic management field: An author co-citation analysis. Strategic Management Journal, 29(3): 319-336.

Noack, A. 2007. Unified quality measures for clusterings, layouts, and orderings of graphs, and their application as software design criteria.Berlin: Universitätsbibliothek.

Peng, M. W., \& Zhou, J. Q. 2006. Most cited articles and authors in global strategy research. Journal of International Management, 12(4): 490-508.

Ramos-Rodríguez, A. R., \& Ruíz-Navarro, J. 2004. Changes in the intellectual structure of strategic management research: A bibliometric study of the Strategic Management Journal, 1980-2000. Strategic Management Journal, 25(10): 981-1004.

Small, H. 1973. Co-citation in the scientific literature: A new measure of the relationship between two documents. Journal of the American Society for Information Science, 24(4): 265-269.

Weiwen Li (PhD, The Chinese University of Hong Kong) is an assistant professor at Sun Yat-sen Business School, Sun Yat-sen University. His research interests include international entrepreneurship, strategic leadership, and corporate governance. He has published papers in the Journal of International Business Studies and Asia Pacific Journal of Management.

Peter Ping Li (PhD, George Washington University) is professor of Chinese Business Studies at Copenhagen Business School, Denmark. Adopting the Chinese frame of Yin-Yang balance with the holistic, dynamic, and duality dimensions, his research focuses on integrating the Western theories with the indigenous perspectives of the East. He is the Editor-in-Chief of the Journal of Trust Research and on the editorial boards of the Journal of Management Studies, Management and Organization Review, and Asia Pacific Journal of Management.

Cheng Shu (MA, University of Rochester) is a doctoral student in entrepreneurship and innovation at the University of Missouri, Kansas City (UMKC). Prior to enrolling at UMKC, he worked for a start-up company in fuel cell. He holds a Master's degree in technical entrepreneurship and management (TEAM) from the University of Rochester, and a BE in materials science and engineering from Shanghai University. His research interest focuses on geographic cluster and social network with respect to entrepreneurship.

Meihua Zhou is a doctoral student at Sun Yat-sen Business School, Sun Yat-sen University. His research interests include corporate governance and internal control. 